\title{
Crisis económica y Sector Público en los países desarrollados
}

\author{
Antonio GONZÁLEZ TEMPRANO \\ Facultad de Ciencias Políticas y Sociología / Universidad Complutense de Madrid \\ temprano@cps.ucm.es
}

Recibido: 03/02/2014

Aceptado: 11/04/2014

\begin{abstract}
Resumen
El trabajo tiene por objeto examinar las interrelaciones entre las recesiones de 1929, 1973 y 2008 y las transformaciones que suceden en las cuentas del Sector Público de las economías avanzadas, concediendo una atención especial a la crisis de 2008. Con tal fin, se analiza la evolución de los ingresos, gasto, saldo presupuestario, deuda e intereses de ésta de la OCDE y UE, así como de las ocho grandes economías desarrolladas. Ello permite conocer el papel desempeñado por las cuentas públicas en cada una de esas fluctuaciones y los cambios operados en la política fiscal a partir de las mismas. Las crisis de 1929 y 2008 han sido las que han provocado alteraciones más acusadas en la política presupuestaria.
\end{abstract}

Palabras clave: crisis económica, Sector Público, cuentas públicas, déficit público, deuda pública.

\begin{abstract}
The main goal of this paper is to analyze the interrelations between the 1929, 1973 and 2008 economic recessions, with special attention to the change in the Public Sector during the last crisis. In order to fulfill this target the focus relies on the study of public revenue, expenditure, budget balance, debt and interest rates evolution in OECD, EU and the eight developed economies. As a result, it is possible to know the role played by public accounts in the different economic crises and the consequent fiscal policy adjustments, to conclude that the 1929 and 2008 recessions have been the ones with biggest impact in budget policy.
\end{abstract}

Economic crisis and public sector in developed countries

Key words: economic crisis, Public Sector, public accounts, public deficit, public debt.

\section{Referencia normalizada}

González Temprano, A. (2014). "Crisis económica y Sector Público en los países desarrollados". Cuadernos de Gobierno y Administración Pública, Vol. 1, Núm. 1: 57-75.

Sumario: Introducción. 1. Nuevo golpe de timón. 2. La antesala fiscal de la recesión. 3. Se disparan los desequilibrios fiscales. 4. Cambio de rumbo. 5. Bibliografía.

\section{Introducción}

Las tres grandes recesiones acontecidas en el último siglo (1929, 1973 y 2008) presentan, entre otras, dos notas comunes. Una es que, en mayor o menor medida, han provocado una reestructuración del intervencionismo estatal, de suerte que remodelación económica y cambios en el Sector Público han evolucionado de forma paralela. La segunda nota es que esas recesiones han causado una crisis de paradigmas en el análisis económico, particularmente, las dos primeras. Se evidencia, una vez más, que 
las fluctuaciones profundas son un antídoto contra la resistencia de la Economía al cambio de paradigmas. Como ha señalado Kahneman (2012: 464), el primer psicólogo en recibir el Nobel de Economía, "en las ciencias sociales, incluida la economía, las creencias teóricas son sólidas, y hace falta mucho más que un hallazgo embarazoso para que unas teorías establecidas sean seriamente cuestionadas".

La crisis de 1929 inaugura una etapa, que se extiende hasta 1973, marcada por la ampliación sustancial de las funciones que hasta entonces había desempeñado el Estado liberal ${ }^{1}$. En palabras de Musgrave (1991: 7-16), el intervencionismo emergente se ocupa de asignar, estabilizar y distribuir rentas, es decir, el Estado se implica directamente en la consecución del crecimiento económico y la cohesión social. A partir de los años treinta, Estado y mercado son las dos instituciones que vertebran económica y socialmente los países avanzados (Habermas, 2001: 102), especialmente los europeos por ser ellos donde el nuevo intervencionismo alcanza cotas más elevadas.

El moderno recurso al Estado refleja la desconfianza en los mecanismos del mercado liberal para garantizar un crecimiento económicamente estable y socialmente integrador, y simultáneamente la confianza en la capacidad del Estado para subsanar las limitaciones del mercado, de ahí que se le trasvase parte de los roles de éste. Pero no conforme con ello, se asignan al Estado funciones que habían sido ajenas al mercado. Por este motivo, la finalidad del intervencionismo emergente no se limita a corregir los fallos de funcionamiento del mercado liberal, su objeto es bastante más ambicioso: pivotar la creación de una nueva sociedad. Estamos ante una etapa de constructivismo social, cuyo esplendor se extiende desde el final de la Segunda Guerra Mundial (SGM, a partir de ahora) hasta la crisis de 1973.

El ejercicio de estas funciones por parte del Estado causa no pocos efectos en él, entre los que cabe destacar: la multiplicación de su presencia en la actividad productiva y regulatoria; erigirse en proveedor de prestaciones sociales, al objeto de garantizar ciertos niveles de protección y promoción social a todos los ciudadanos; finalmente, aparecer como agente redistribuidor de rentas, alterando la asignada por el mercado. El presupuesto público se convierte por esta vía en uno de los ejes del desenvolvimiento económico moderno, hasta el extremo de que no puede entenderse éste sin considerar dicho presupuesto.

La larga expansión económica que sigue a la $\mathrm{SGM}^{2}$, la eclosión del bienestar social y la asimilación de estos fenómenos con el intervencionismo, refuerza la confianza en el Estado durante estos años. Su legitimidad alcanza cotas sin precedentes, y no conforme con ello desempeña un importante lugar en la legitimación del sistema (Habermas, 1973). En consecuencia, el intervencionismo posbélico acrecienta la legitimidad del Estado y del capitalismo.

\footnotetext{
${ }^{1}$ Las funciones atribuidas al Estado por el pensamiento liberal se fundamentaron en las designadas por (Smith, 1983: 454 y 455).

${ }^{2}$ Frente a los que atribuyen el crecimiento económico de estas décadas al intervencionismo, Hicks (1976: 10 y 11) sostiene que no existe fundamente para tal identificación.
} 
Este intervencionismo articula un modelo de crecimiento con una elevada capacidad integradora. Nos hallamos ante un capitalismo de masas en el que el Estado deja de ser y percibirse como correa de transmisión del gran capital, tal como había sido interpretado por el marxismo tradicional; una de las expresiones más nítida de esta interpretación se encuentra en la obra de Lenin (2006).

La democratización del Estado y su creciente autonomía frente a los diferentes grupos sociales no evita la existencia de contradicciones en su seno. Muy al contrario, éstas se multiplican, como no podía ser de otra manera cuando el Estado pretende erigirse como una institución por encima de intereses encontrados, que ha de conciliar y hacerlo en un marco de libertades políticas y sindicales. Hasta la etapa posbélica, el Estado nunca había gozado de tanta legitimidad ni acumulado tal cantidad de contradicciones sistémicas, hasta el extremo de aparecer como un crisol de éstas (Poulantzas, 1973: 52, 53 y 237-240).

El análisis económico no permanece ajeno a estos avatares. Participa en ellos dándoles un marco teórico, conocido como Teoría de los fallos del mercado. Emprendida por Pigou y desarrollada por Kalecki y el denominado circus de Cambridge, en el que su figura señera es J. M. Keynes, esta doctrina elabora un cuerpo analítico en el que, tras significar las limitaciones del mercado liberal para garantizar en el largo plazo la estabilidad económica y pleno empleo, propone un intervencionismo de nuevo cuño. El fin básico de este intervencionismo es combatir las fluctuaciones económicas profundas mediante políticas de reactivación, con lo que el Estado contribuye a estabilizar la demanda global; el instrumento fundamental a emplear es, además de la política monetaria, la ampliación del gasto público, aún a riesgo de incurrir en déficit público, que se absorberá con la reactivación económica. Esta doctrina supone una ruptura con el pensamiento clásico y neoclásico en la forma de entender el desarrollo y la intervención del Estado.

\section{Nuevo golpe de timón}

La crisis de 1973, comúnmente conocida como crisis del petróleo, y la remodelación económica que le sigue, clausuran las décadas doradas del capitalismo e intervencionismo, provocando una nueva inflexión en la presencia del Estado en la economía. El giro que experimenta el intervencionismo a partir de esa crisis es de signo contrario a la de los años treinta: debilitamiento del Sector Público y reforzamiento de los mecanismos del mercado como reguladores de la actividad económica, no así de la social en la que el Estado sigue desempeñando una labor clave. Lo sucedido en la economía durante esta nueva fase se podría simplificar en los términos siguientes: más mercado y menos Estado.

El debilitamiento del Sector Público a partir de 1973 responde a un conjunto de factores, entre los que destaca: fallos mostrados por el Estado en las décadas precedentes; limitaciones para combatir la crisis económica de 1973; desequilibrios económicos derivados del déficit público crónico y aumento progresivo de la deuda pública desde 1974; irrupción de valores sociales muy diferentes a los posbélicos; y, como resultado, mayor confianza en el mercado para responder a la demanda de mayor eficiencia y competitividad formulada por una economía cada vez más globalizada. 
Tal debilitamiento se plasma de diversas formas, como son la privatización de empresas públicas, la reducción de la potestad regulatoria del Estado en favor del mercado y, finalmente, el control del gasto público a partir de los años ochenta. Aún con todo, las economías avanzadas siguen siendo mixtas; lo prueba, por ejemplo, el peso que sigue teniendo el Estado en la esfera productiva y regulatoria y el elevado gasto público en porcentaje del PIB $^{3}$. Al igual que tras la SGM, el Reino Unido vuelve a liderar la nueva revolución económica.

En consecuencia, la ola reprivatizadora alcanza una altura bastante menor de lo que algunos han querido ver. El Estado sigue desempeñando un papel fundamental en la estructuración de las sociedades desarrolladas, particularmente en el ámbito social, en el que "la vuelta a los cuarteles de invierno" es muchísimo menos acusada que en la esfera propiamente económica.

Las cuentas del Sector Público no permanecen ajenas a los cambios que suceden a la recesión de 1973. Una de las novedades es que a partir de 1974 su saldo incurre en déficit prácticamente crónico en la mayoría de las economías avanzadas. Las causas de este desequilibrio fiscal son, por el lado de los ingresos, una tasa de crecimiento económico muy inferior a la alcanzada tras la SGM, lo que implica un aumento también menor de recaudación; por el lado del gasto, tendencia estructural a un incremento adicional notable, agudizado por la aparición de un entorno social nuevo que afecta sobremanera a las partidas destinadas a prestaciones sociales ${ }^{4}, \mathrm{y}$ una tasa natural de desempleo que duplica la existente en las décadas posbélicas. El mantenimiento del modelo socioeconómico inaugurado tras la SGM muestra a partir de la crisis del petróleo signos inquietantes de sostenibilidad financiera, tal como hemos enunciado.

Estos desafíos que acompañan al Sector Público se agravan por un rasgo permanente de éste, su menor eficiencia, problema no fácil de resolver por razones sociales, políticas y económicas. Lo preocupante es que tal problema afecta a un volumen de gasto que representa en torno al 40 por ciento del PIB; a nuestro entender, el mayor reto del Sector Público no es tanto su elevado volumen de gasto, como su baja eficiencia y las dificultades para subsanarla. En este sentido merece subrayarse que, frente a la reestructuración acometida por el sector privado para aumentar su eficiencia tras la crisis de 1973, el Sector Público continúa padeciendo una patología muy similar a la mostrada desde la aparición del nuevo intervencionismo: baja eficiencia, notable tendencia estructural del gasto a la expansión y cierta instrumentación por parte de partidos políticos, sindicatos y organizaciones empresariales. A pesar de algunos esfuerzos por incrementar la eficiencia del Sector Público, como son los realizados por el Gobierno de la Sra. Thatcher en el Reino Unido, este reto sigue

\footnotetext{
${ }^{3}$ En 2007, es decir, antes de que eclosione la recesión de 2008, el gasto público representa el 39,2 por ciento del PIB en el conjunto de la OCDE y el 45,6 por ciento en la UE27.

${ }^{4}$ Entre las novedades que presenta el entorno social de finales del siglo XX y principios del XXI, en relación con el existente tras la SGM, figura el creciente envejecimiento demográfico, que dispara el gasto en sanidad y pensiones.
} 
despertando, sorprendentemente, escaso interés en la sociedad civil y política (Harrison, 1991: 163-168).

De acuerdo con lo sucedido entre la crisis de 1973 y 2007, se puede afirmar que el Estado cosecha mayores éxitos en su contribución a la cohesión social que en ampliar su eficiencia. Atendiendo a los niveles alcanzados por el gasto público, uno de los grandes desafíos con que se enfrentan en esas décadas las economías avanzadas es la escasa conciliación de eficiencia y equidad por parte del Estado (Alonso, 2005), al que, dicho sea de paso, una parte no pequeña de la sociedad percibe como un padre con recursos ilimitados, que los obtiene sin el esfuerzo de los ciudadanos y está obligado a ejercer una labor sobreprotectora con todos ellos.

La permanencia del déficit público entre 1974 y 2007 en las economías avanzadas no está alejada de intereses políticos, como han enfatizado los componentes de la Public Choice, Buchanan y Wagner (1983: 158-160). Por motivos electorales, los gobiernos tienden a mantener ese desequilibrio fiscal antes que afrontar el coste político de las distintas opciones para combatirlo: reducir el gasto y/o aumentar la presión fiscal.

La confluencia de factores económicos e institucionales origina, pues, que buena parte de las economías avanzadas emprendan en 1974 una experiencia histórica que no tiene precedentes ni en el ámbito de las políticas públicas ni del análisis económico, cual es un déficit crónico que se va a extender, en el mejor de los casos, durante medio siglo, como tendremos ocasión de comprobar en las próximas páginas.

En efecto, la existencia del déficit crónico vulnera tanto los principios smithianos de equilibrio presupuestario, que alumbran las políticas públicas hasta la crisis de Wall Street, como los de la Teoría de los fallos del mercado, en particular, los de Kalecki y Keynes (1998), quienes postulan la expansión del gasto en fases recesivas, sin importar incurrir en déficit, y retornar al equilibrio presupuestario una vez recuperada la demanda privada. Con independencia del posicionamiento que se tenga ante las doctrinas de estos autores, entendemos que, cuando menos, resulta polémico aplicar el calificativo de keynesianas a las políticas fiscales posteriores a 1973.

La ruptura de las políticas públicas posteriores a 1973 con las propuestas de Kalecki y Keynes no acaban ahí, se extienden a la forma mayoritaria de financiar el déficit: mediante deuda pública, como hemos adelantado. La existencia de un déficit público crónico y el recurso a la deuda provocan la eclosión de ésta, de forma que una parte creciente del gasto ha de destinarse al pago de intereses, no a la creación de riqueza y/o a la ampliación del bienestar social ${ }^{5}$; queda así desnaturalizado el objeto de la deuda. A partir de la crisis del petróleo la Hacienda Pública se adentra en una nueva etapa.

El endeudamiento público tiene asimismo un trasfondo político: permite mantener un gasto elevado sin que ello suponga un incremento de la presión fiscal en proporción semejante, lo que reporta réditos electorales. Se premia así a los votantes en

\footnotetext{
${ }^{5}$ La deuda pública para el conjunto de la OCDE pasó de representar el 36,9 por ciento del PIB en 1974 a ser el 74,3 por ciento en 2007.
} 
perjuicio de las generaciones futuras que tendrán que cargar con una parte de la deuda sin que nadie les haya consultado; se antepone el bienestar de los votantes al de las generaciones futuras, máxime cuando la deuda está causada, como es el caso durante estas décadas, por un incremento de gasto destinado en su mayor parte al consumo, no a la inversión productiva, lo que favorece la "descapitalización" de la economía, la caída de la productividad y la pérdida de competitividad en los mercados internacionales, amén de reducir la liquidez del sistema bancario, impulsar el encarecimiento del precio del dinero, dificultar el acceso de las PYMES al crédito y desplazar la inversión privada con el consiguiente impacto negativo sobre el empleo. En estas circunstancias, parece lógico que se reavive un debate tan antiguo como la propia Economía: la oportunidad de recurrir permanentemente a la deuda pública para financiar el déficit.

El aumento de la deuda pública, además de ir ampliando el peso del pago de intereses en el presupuesto público y provocar los efectos expuestos, reduce la capacidad de la política presupuestaria para combatir las fluctuaciones económicas ${ }^{6}$, pues contrae los recursos que puedan destinarse a políticas expansivas para combatir ésas, salvo que se opte por un mayor endeudamiento. La elevada deuda pública en que van adentrándose las economías avanzadas desde mediados de los años setenta abre las puertas a un conjunto de desequilibrios que debilitan el crecimiento económico y los ingresos públicos, con el consabido efecto sobre el déficit y la deuda. Estas economías se hallan inmersas en un proceso que favorece la aparición de una espiral de distorsiones económicas y fiscales que se retroalimentan.

De acuerdo con el panorama descrito, puede entenderse que los gobiernos no puedan permanecer impasibles a los desequilibrios fiscales. Para combatirlos proceden a realizar un conjunto de consolidaciones fiscales en los años ochenta y noventa, cuyo objetivo básico no es tanto reducir el gasto como aminorar su ritmo de crecimiento con el fin de disminuir el déficit público; el acortamiento de éste emerge como una de las metas de las políticas públicas. En el caso de la UE, la lucha contra el déficit público adquiere carácter institucional en el Tratado de Maastricht, suscrito en 1992, al pronunciarse por la conveniencia del equilibrio presupuestario y establecer como una de las condiciones para acceder a la Unión Monetaria que el déficit no supere el 3 por ciento del PIB y el techo de deuda el 60 por ciento de este indicador.

Las consolidaciones fiscales consiguen moderar el crecimiento del gasto, de modo que éste tiende a evolucionar de forma paralela al PIB, más se muestran insuficientes para acabar con el déficit; éste requiere ajustes de gasto más ambiciosos, pero hay el riesgo, por no decir seguridad, de tener que pagar un coste electoral elevado. Atendiendo al ritmo de crecimiento económico de estas décadas, la resistencia a realizar ajustes de gasto en profundidad no deja otra opción para terminar con el déficit público que incrementar significativamente la presión fiscal, posibilidad que la impiden dos obstáculos. Uno, económico: no parece razonable en economías que ya soportan

\footnotetext{
${ }^{6}$ El pago de intereses de la deuda para el conjunto de la OCDE pasa de representar el 0,87 por ciento del PIB en 1974 a ser en 2007 el 1,76 por ciento.
} 
cuantiosos impuestos, menos aun teniendo presente el riesgo de pérdida de competitividad en los mercados internacionales. El otro obstáculo es político: la pérdida de apoyo electoral. Factores económicos e institucionales condenan al déficit crónico y a los efectos citados.

Una de las consecuencias de los fenómenos señalados es el cambio en la percepción del Estado: de ser considerado instrumento eficaz en la lucha contra las fluctuaciones, va apareciendo como origen de desequilibrios, sobre todo en materia fiscal. El fracaso, al menos parcial, del intervencionismo en la consecución de su principal objetivo económico, aliviar las fluctuaciones graves, contribuye decisivamente al cuestionamiento del intervencionismo desarrollado tras la SGM y al rearme del mercado. El Estado pierde parte de la legitimidad disfrutada en el ámbito económico (González Temprano, 2010: 5 y 6), no así en el de la cohesión social, donde continúa contando con el apoyo de la inmensa mayoría de la población, como reflejan las encuestas del momento.

Son dos los motivos principales que evitan que la pérdida de legitimidad del Estado se traduzca en crisis de legitimidad sistémica, cuando ésta se hallaba tan vinculada al intervencionismo. Por una parte, el rearme del mercado y fortalecimiento de la confianza en él depositada. Por la otra, el mantenimiento de la política de cohesión social a través del Estado de Bienestar. La crisis del petróleo abre una etapa en la que el mercado amplía su protagonismo en la actividad económica y en la legitimación sistémica, mientras que la legitimación del Estado queda parcialmente relegada a la cohesión social. Desde entonces la legitimación del Estado y su aportación a la del sistema estarán más conectadas al bienestar social, lo que no deja de ser un desafío para el Sector Público por los problemas de sostenibilidad financiera que presenta el Estado de Bienestar.

Los cambios en el análisis económico que suceden a la crisis de 1973 no son inferiores a las transformaciones económicas: se asiste a una crisis de paradigmas no menos acusada que la habida cuatro décadas antes. La realidad que emerge a partir de 1973 cuestiona la doctrina hegemónica tras la SGM, la Teoría de los fallos del mercado, y favorece su sustitución por la oponente, la Teoría de los fallos del Estado (González Temprano, 1998: 19 y 20). Esta corriente de pensamiento engloba un conjunto de aportaciones de muy amplio espectro ideológico, cuya nota común es enfatizar las contradicciones del Estado en las sociedades desarrolladas y democráticas, y las limitaciones que de ello se derivan para combatir los errores del mercado, de manera que a los fallos de éste se añaden los del Estado. Estamos ante la segunda gran crisis del análisis económico. 


\section{La antesala fiscal de la recesión}

La etapa iniciada en 1973 concluye en 2007, último ejercicio expansivo antes del estallido de la recesión en $2008^{7}$. En esa fecha, la mayoría de las ocho grandes economías avanzadas (Alemania, Canadá, España, Estados Unidos, Francia, Italia, Japón y Reino Unido), así como la media de la Eurozona17, UE27 y OCDE, siguen soportando déficit público (Cuadro 1), a pesar de los buenos resultados económicos obtenidos en el ejercicio. Salvo en España y Reino Unido, la deuda pública sobrepasa el índice de intolerancia fijado en el Tratado de Maastricht (60 por ciento del PIB), y el pago de intereses persiste como uno de los factores a tener presente para explicar el incremento del gasto y el déficit, pese al descenso experimentado en porcentaje del gasto público en fechas anteriores ${ }^{8}$; en el caso de las cinco primeras economías europeas, los intereses oscilan entre el 4,1 por ciento del gasto público de España y el 10,4 por ciento de Italia.

En la antesala de la tercera gran recesión, las cuentas públicas de estas economías continúan, después de más de tres décadas, sin corresponder a lo que lo que se ha entendido tradicionalmente por buen gobierno (Marhall, 2005: 72-73 y 765-773). Desde el punto de vista del análisis económico, el panorama de las cuentas públicas en 2007 poco tiene que ver con los preceptos de la Teoría de los fallos del mercado, se aproxima más a lo diagnosticado por la Teoría de los fallos del Estado.

Antes de que la recesión eclosione en 2008, lo que diferencia a las cuentas públicas de la mayor parte de las economías avanzadas no es si están o no saneadas, sino el volumen de sus desequilibrios. Ello va a condicionar la capacidad de la política presupuestaria para combatir una hipotética crisis económica: en la medida que el déficit y la deuda representen un porcentaje mayor del PIB, los gobiernos verán reducido su potencial para afrontar una fluctuación.

\footnotetext{
${ }^{7}$ Soros (2008) fija el estallido de la crisis en agosto de 2007 cuando los bancos centrales intervienen para proporcionar liquidez al sistema bancario.

${ }^{8}$ En el caso de la Eurozona 17, el pago de intereses pasa de representar el 10,2 por ciento del gasto público en 1995 a ser el 6,5 por ciento en 2007.
} 
Tabla 1. Gastos, saldos y deuda de las Administraciones Públicas en \% del PIB, 2007-2012.

\begin{tabular}{|l|l|l|l|l|l|l|l|l|l|l|l|l|l|l|l|l|l|l|}
\hline & \multicolumn{9}{|c|}{ Gasto público en \% del PIB } & \multicolumn{7}{|c|}{ Saldos de las cuentas públicas en \% del } & \multicolumn{6}{c|}{ Deuda pública bruta en \% PIB } \\
\hline & 2007 & 2008 & 2009 & 2010 & 2011 & 2012 & 2007 & 2008 & 2009 & 2010 & 2011 & 2012 & 2007 & 2008 & 2009 & 2010 & 2011 & 2012 \\
\hline Alemania & 43,4 & 43,4 & 44,1 & 48,2 & 47,8 & 45,4 & 0,2 & $-0,1$ & $-3,1$ & $-4,2$ & $-0,6$ & 0,2 & 65,6 & 69,9 & 77,5 & 86,1 & 86,3 & 89,2 \\
\hline Canadá & 38,4 & 39,0 & 43,4 & 43,0 & 41,8 & 41,2 & 1,4 & $-0,3$ & $-4,8$ & $-5,2$ & $-4,0$ & $-3,2$ & 65,0 & 69,2 & 81,5 & 83,0 & 83,4 & 85,5 \\
\hline España & 39,2 & 39,2 & 41,5 & 46,3 & 46,3 & 45,2 & 1,9 & $-4,5$ & $-11,2$ & $-9,7$ & $-9,4$ & $-10,6$ & 42,4 & 47,7 & 62,9 & 67,8 & 77,1 & 90,5 \\
\hline EEUU & 36,9 & 36,9 & 39,1 & 42,8 & 42,7 & 41,6 & $-2,9$ & $-6,6$ & $-11,9$ & $-11,4$ & $-10,2$ & $-8,7$ & 66,3 & 75,3 & 88,8 & 97,9 & 102,3 & 106,3 \\
\hline Francia & 52,6 & 52,6 & 53,3 & 56,8 & 56,6 & 56,1 & $-2,7$ & $-3,3$ & $-7,6$ & $-7,1$ & $-5,3$ & $-4,5$ & 73,0 & 79,3 & 91,3 & 95,6 & 99,5 & 109,7 \\
\hline Italia & 47,6 & 47,6 & 48,6 & 51,9 & 50,4 & 49,9 & $-1,6$ & $-2,7$ & $-5,4$ & $-4,3$ & $-3,7$ & $-2,9$ & 114,4 & 116,9 & 130,1 & 128,9 & 122,0 & 140,2 \\
\hline Japón & 35,8 & 35,8 & 36,9 & 41,9 & 40,8 & 42,7 & $-2,1$ & $-1,9$ & $-8,8$ & $-8,3$ & $-8,9$ & $-9,9$ & 162,4 & 171,1 & 188,7 & 193,3 & 210,6 & 219,1 \\
\hline R. Unido & 43,7 & 43,7 & 47,6 & 50,8 & 50,2 & 48,6 & $-2,8$ & $-4,9$ & $-10,9$ & $-10,0$ & $-7,9$ & $-6,5$ & 47,0 & 57,5 & 72,0 & 85,6 & 100,4 & 103,9 \\
\hline Eurozona17 & 46,1 & 47,2 & 51,2 & 51,0 & 49,5 & 49,9 & $-0,7$ & $-2,1$ & $-6,4$ & $-6,2$ & $-4,2$ & $-3,7$ & 66,4 & 70,2 & 80,0 & 85,4 & 87,3 & 90,6 \\
\hline UE27 & 45,5 & 47,0 & 51,0 & 50,5 & 49,0 & 49,3 & $-0,9$ & $-2,4$ & $-6,9$ & $-6,5$ & $-4,4$ & 4,0 & 59,0 & 62,3 & 74,6 & 80,0 & 82,5 & 85,3 \\
\hline OCDE & 39,2 & 39,2 & 41,0 & 44,5 & 44,0 & 43,2 & $-1,3$ & $-3,4$ & $-8,2$ & $-7,7$ & $-6,4$ & $-5,7$ & 74,3 & 80,9 & 92,3 & 98,9 & 103,5 & 108,8 \\
\hline
\end{tabular}

Fuente: OCDE y Eurostat

Nota: La deuda pública de la Eurozona17 y la UE27 está consolidada.

Si observamos la Tabla 1, es fácil colegir que en 2007 las cuentas públicas de esas economías no se hallan en posición favorable para abordar una crisis, mucho menos de la gravedad que va a alcanzar la de 2008. Se colige también que esas cuentas públicas ofrecen muchas probabilidades de deteriorarse gravemente por el impacto de una crisis económica, hasta el punto de convertirse en uno de sus dinamizadores; actuarían como un pirómano abriendo nuevos frentes. En síntesis, la situación de las cuentas públicas en 2007 es inquietante, pero no lo suficiente como para causar una crisis económica, mucho menos como la que eclosiona en 2008.

Algunos de los datos sobre los que fundamentamos estas afirmaciones son los siguientes: la deuda pública de seis de las ocho grandes economías avanzadas alcanza en 2007 el índice de intolerancia establecido por la UE (60 por ciento del PIB), y las otras dos sobrepasan el 40 por ciento; los intereses de las primeras economías europeas, salvo la española, superan con creces el 2 por ciento del PIB; finalmente, estos intereses absorben, con la excepción de España, más del 5 por ciento del gasto público, alcanzando en Italia el 10,4 por ciento. El estado de las cuentas públicas de estas economías en 2007 se asemeja a un volcán dormido con elevado potencial destructor; en este caso, falta la presencia de un elemento parcialmente externo que lo haga eclosionar.

De estos datos se colige que en 2007 hay dos economías cuyas cuentas públicas se encuentran en posiciones muy diferentes para afrontar una hipotética crisis económica, España e Italia. De las ocho grandes economías avanzadas, España es en esa fecha la mejor posicionada fiscalmente para combatir una fluctuación, mientras que Italia ocupa el extremo opuesto. 
A pesar de esa ventajosa posición fiscal, la economía española es, de las ocho grandes, la que sufre una recesión más profunda y dilatada (se extiende hasta el tercer trimestre de 2013). A partir de 2008, los desequilibrios fiscales eclosionan en ella con tal fuerza que contribuyen notablemente a ampliar los efectos de la crisis económica y financiera, lo que a su vez agrava el estado de sus cuentas públicas. Lo sucedido en España desde 2008 es uno de los muchos ejemplos de retroalimentación de crisis económica, financiera y de deuda soberana, con la peculiaridad de que en esta oportunidad el agravamiento de los desajustes fiscales no son tanto la causa como la consecuencia de la fluctuación económica y financiera.

Una de las lecciones que puede extraerse de ello es que las cuentas públicas saneadas acrecientan la capacidad del Estado para afrontar la crisis económica, pero dicha capacidad depende también de otras variables, como son los rasgos de la contracción económica y la gestión de ésta y de los desajustes fiscales. Si no se tienen en cuenta los factores que trascienden el estado de las cuentas públicas, difícilmente puede entenderse que a partir de 2008 España sea la peor parada fiscal, financiera y económicamente, más aún que Italia, a pesar de que en 2007 ésta presenta unas cuentas mucho más desequilibradas. Por no hablar del país que sale reforzado de la crisis respecto de sus homónimos europeos, Alemania, cuyas cuentas públicas presentan en 2007 unos desajustes bastante más agudos que los de España.

La conclusión final a la que invita la comparativa de las cuentas públicas de las ocho primeras economías avanzadas en 2007 es que no es fácil demostrar que el origen de la recesión económica de 2008 obedezca a distorsiones fiscales previas, los datos refutan tal posibilidad. El origen de la crisis se halla en la confluencia de un conjunto de factores distanciados de los desajustes fiscales $\left({ }^{9}\right)$; ni el nivel de deuda pública, ni el pago de la misma, como tampoco el gasto público, pueden considerarse, a nuestro entender, causa de la recesión, como lo prueba que el déficit público responda en mayor medida a la disminución de ingresos que al exceso de gasto.

Hay que enfatizar también que el agravamiento de los desequilibrios fiscales desde 2008 tiene su origen en el impacto de la recesión económica y financiera sobre las cuentas públicas (contracción de la recaudación y aumento del gasto), y que este agravamiento aviva la crisis económica, de suerte que no es posible entender la evolución de ésta sin contemplar los desajustes presupuestarios. Como hemos expresado, crisis económica, fiscal y financiera se retroalimentan. En la recesión de 2008 acontece un fenómeno que no es nuevo: las variaciones de los saldos presupuestarios son consecuencia, no causa, de las fluctuaciones económicas (Krugman, 2013: 441). La peculiaridad reside en que los desajustes fiscales alcanzan tal magnitud a partir de 2008 que terminan por ampliar la crisis económica y financiera, de forma que la que,

${ }^{9}$ Entre esos factores hay que apuntar el encarecimiento de alimentos y materias primas, desequilibrios en la balanza de pagos, y sobre todo un exceso de ahorro mundial que facilita el acceso al crédito, aún de alto riesgo. Esto sienta las bases para la aparición de burbujas económicas, particularmente en el sector inmobiliario. En una economía interconectada, esta crisis adquiere rápidamente un carácter global, azotando con especial virulencia a las economías avanzadas al ser ellas donde se concentran las burbujas económicas. 
además de fortalecer la Teoría de los fallos del Estado, obliga a los gobiernos superación de ésta requiere combatir tales desajustes.

Así pues, al igual que en 1974, en 2008 las cuentas del Estado emergen como uno de los mecanismos impulsores de la recesión. La diferencia es que en 1974 la deuda alcanza niveles muy inferiores a los de 2008 debido a que en 1973 es sensiblemente menor que en $2007^{10}$. Ello significa que las cuentas públicas desempeñan un papel menos desestabilizador en la crisis del petróleo que en la denominada Gran Recesión, fenómeno a adoptar cambios más radicales en las políticas presupuestarias.

\section{Se disparan los desequilibrios fiscales}

Otra diferencia entre la crisis del petróleo y la Gran Recesión es que el déficit público alcanza en ésta niveles bastante más elevados. Mientras que en 1974 el déficit representa el 1,5 por ciento del PIB en el conjunto de la OCDE, en 2008 es el 3,4 por ciento, elevándose al 8,2 por ciento en 2009, para descender a partir de este ejercicio. En la UE27, observamos un proceso similar: la eclosión del déficit de 2008 llega a su cenit en 2009, en que significa el 6,9 por ciento del PIB, reduciéndose también desde entonces.

Pese a la contracción experimentada por el déficit público a partir de 2010, éste todavía representa en 2012 el 5,7 por ciento del PIB en el conjunto de la OCDE y el 4,0 por ciento en la UE27 (Cuadro 1). De acuerdo con la índice de intolerancia de déficit fijado en el Tratado de Maastricht, la OCDE y la UE27 no dejan de padecer entre 2008 y 2012 niveles de déficit favorecedores de desequilibrios económicos estructurales. Sentado este principio, estimamos conveniente hacer algunas precisiones sobre lo acontecido en los ejercicios en los que la recesión económica, fiscal y financiera es más acusada, 2008 y 2009.

En términos de volumen, el déficit se dispara en 2008 y 2009 y se reduce desde 2010 (Gráfico 1). En el caso de la UE27, ese volumen es en 2009 un 626,6 por ciento mayor que en $2007^{11}$, mientras que entre 2010 y 2012 disminuye un 35,8 por ciento ${ }^{12}$. La causa de esa eclosión obedece a la reducción de ingresos, provocada por el debilitamiento de la actividad económica, particularmente en 2009, y a un incremento de gasto adicional, especialmente en 2008, motivado por la activación de los estabilizadores automáticos, como prestaciones por desempleo. No obstante, conviene señalar que la ampliación del gasto en este bienio no responde tanto a la activación de los estabilizadores automáticos como a su tendencia estructural a la expansión, ésta es la responsable de tres cuartas partes, aproximadamente, de la ampliación del gasto. Ello

\footnotetext{
${ }^{10}$ La deuda pública en 1973 representa el 38,3 por ciento del PIB en el conjunto de la OCDE y el 42,4 por ciento en la Eurozona15. En 2007, la deuda de la OCDE se eleva al 74,3 por ciento y la de la Eurozona15 al 72,3 por ciento.

${ }^{11}$ El déficit de la UE27 en 2007 es de 111.209,4 millones de euros, en 2009 de 807.996,2 y en 2010 de $800.889,3$. En las mismas fechas la Eurozona17 arroja un déficit de 61.195,7 millones de euros, $567.420,3$ y $569.407,8$, respectivamente.

${ }^{12}$ El déficit de la UE27 en 2012 asciende a 514.087,8 millones de euros. El de la Eurozona17 a $352.682,7$ millones.
} 
significa que el estallido del déficit, aún en los momentos más agudos de la crisis, está más motivado por la caída de los ingresos que por exceso de gasto.

\section{Cambio de rumbo}

Las políticas de consolidación fiscal empiezan a dar sus frutos en 2010. Como se ha indicado en páginas anteriores, el déficit público dibuja desde entonces una curva descendente, hasta el extremo de alcanzarse superávit en Alemania en 2012 (Cuadro 1). Aún con todo, el conjunto de la OCDE, la UE27 y el resto las economías avanzadas, excepto Canadá e Italia, continúan en ese ejercicio padeciendo un déficit sensiblemente superior al índice de intolerancia establecido en el Tratado de Maastricht, por lo tanto, siguen arrastrando desajustes fiscales favorecedores de desequilibrios estructurales.

A partir de 2010 se abre un escenario con dos novedades dignas de mención. Una es que la contracción del déficit tiene lugar en ejercicios que no son precisamente expansivos, a diferencia de lo acontecido desde 1974, etapa en la que contracción de la actividad económica y aumento del déficit habían ido juntos. La segunda novedad es que la reducción del déficit no se produce tanto por un aumento de los ingresos ${ }^{13}$ como por el control del gasto: si en 2008 y 2009 el volumen de gasto de la Eurozona17 aumenta el 4,9 por ciento, en 2010 el incremento es el 2,3 por ciento, en 2011 se produce un decrecimiento del $-0,3$ por ciento y en 2012 la expansión alcanza el 1,6 por ciento; tómese nota de que el control del gasto tiene lugar a pesar de los ingentes recursos que siguen destinándose a las prestaciones por desempleo. Lo sucedido entre 2010 y 2012 invita a pensar que nos hemos adentrado en una fase en la que el ciclo económico tiende a aminorar su impacto sobre los saldos fiscales.

La lección que puede extraerse del devenir de las cuentas públicas desde 2010 es que los efectos económicos, sociales y políticos de la recesión han sido tan profundos que han forzado a políticos, sociedad civil y círculos académicos a cuestionar la tolerancia con los desequilibrios fiscales. En relación con lo sucedido entre 1974 y 2008, tal devenir parece indicar que estamos asistiendo a una crisis de paradigmas sobre el desarrollo económico, el papel del Sector Público y el rol a desempeñar por su presupuesto en la lucha contra las fluctuaciones. Frente a lo mantenido por Reinhart y Rogoff (2011: 312 y 313), entendemos que los gobiernos parecen haber aprendido que hay que pagar un precio demasiado elevado por políticas proclives a gastar frecuentemente por encima de los ingresos; puede ser porque ellos figuran entre las víctimas de tales políticas, como lo certifican las crisis gubernamentales que acompañan a la recesión de $2008^{14}$.

La permanencia del déficit tras 2010 provoca que la deuda pública no deje de crecer (Cuadro1). En la UE27, su volumen aumenta un 12,1 por ciento entre 2010 y

\footnotetext{
${ }^{13}$ En 2010 los ingresos aumentan el 2,6 por ciento, en 2011 el 4,0 y en 2012 el 2,7.

${ }^{14}$ Los cambios de Gobierno en Grecia, Irlanda, España, Eslovenia, Eslovaquia y Holanda están vinculados a las dificultades provocadas por la crisis económica, como también está vinculada a ésta la reelección de la Sra. Merkel, en este caso, por los buenos resultados obtenidos en Alemania.
} 
$2012^{15}$. En términos porcentuales del PIB, el endeudamiento en el conjunto de la OCDE representa en 2012 el 108,8 por ciento y en la UE27 el 85,3 por ciento. Ambos organismos no sólo dejan muy atrás el índice de intolerancia europeo, sino que en el caso de la OCDE se sobrepasa el índice de intolerancia que empieza a barajarse a partir de 2010 (90 por ciento del PIB), y en el de la UE27, se está muy próximo. Hay que enfatizar que en 2012 la deuda es mucho más acusada que en 1974 y $1975^{16}$, lo que refleja la mayor gravedad de la crisis de deuda soberana que estalla en 2008.

Déficit y deuda cuantiosos en 2012 invitan a concluir que, a pesar del éxito cosechado en la lucha contra el déficit público a partir de 2010, dos años más tarde las economías avanzadas siguen presentando cuentas públicas que lastran el crecimiento; el desafío de la deuda soberana continúa presente aún en países que, como Alemania, presentan saldos fiscales positivos. A cuatro años del estallido de la crisis, las cuentas públicas se alzan todavía como elemento desestabilizador. Con este panorama es comprensible que se intensifique el debate sobre la presencia del Estado en la economía, particularmente, sobre las consolidaciones fiscales.

La expansión permanente de la deuda pública provoca un aumento notable de los recursos destinados a su pago $\left({ }^{17}\right)$, pero hay un dato más revelador: la relación de éstos con el déficit público. En 2012, los intereses representan el 74 por ciento del déficit público en la UE27 y el 83,5 por ciento en la Eurozona17. En el seno de las 5 grandes economías europeas el ratio varía de forma sustancial: del 28 por ciento de España al 177,9 por ciento de Italia. No obstante, existe una nota común a la mayor parte de las economías avanzadas: han de pedir nuevos préstamos para hacer frente a las obligaciones de la deuda, en consecuencia, una parte no pequeña de ésta pierde su sentido por cuanto no se destina a reactivar la economía ni ampliar el bienestar social.

Existe otro extremo de la deuda pública que merece también ser estimado: la presencia del pago de intereses en el gasto público. Los datos referidos a la UE27 nos dicen que entre 2007 y 2012 no se han producido cambios sustanciales en tal ratio, oscilando las cinco grandes economías entre el 5 y 6 por ciento del gasto público, excepto Italia que se mueve en torno al 10 por ciento. La causa de que el volumen de intereses aumente durante la recesión, pero no su peso en el gasto público, es la expansión de éste. Lo que interesa subrayar es que los intereses tienen una presencia significativa en el gasto público, hasta el extremo de ser superior al gasto destinado a sanidad o educación en la mayor parte de las economías avanzadas. Una de las consecuencias del creciente endeudamiento público es que obliga a tener presente los intereses de la deuda para explicar en toda su amplitud la evolución del gasto público, incluyendo su tendencia estructural a la expansión.

Lo sucedido con la deuda pública en la recesión de 2008 nos reafirma en lo apuntado sobre ella en páginas anteriores: a nuestro entender, el endeudamiento está difícilmente justificado si no es para afrontar una crisis económica profunda o contin-

\footnotetext{
${ }^{15}$ En 2010, la deuda de la UE27 es de 9.825.305,7 millones de euros, en 2012 de 11.011.797,0 millones.

${ }^{16}$ En 1974, la deuda pública en la OCDE representa el 36,9 por ciento del PIB y en 1975 el 40,3 por ciento.

${ }^{17}$ Los intereses de la UE27 pasan de ser 338.901,9 millones de euros en 2007 a 380.254,5 millones en 2012.
} 
gencia de amplio impacto, como puede ser una guerra o catástrofe. De no ser así, es probable que la deuda siente las bases para que en el largo plazo genere un empobrecimiento social.

Se afirma con frecuencia que la deuda está justificada si se destina a inversión para proporcionar mayor bienestar. Nosotros añadiríamos que está justificada en la medida que siente las bases para proporcionar bienestar a las generaciones que la van a financiar: presente y futuras. De no darse la segunda condición, interpretamos que el endeudamiento equivale a un acto de irresponsabilidad, cuando no de insolidaridad intergeneracional. Dejar un legado de deuda a próximas generaciones para incrementar el bienestar presente difícilmente puede estar éticamente justificado, ¿acaso no se emplea este argumento en temas medioambientales? De cualquier forma, la raíz del problema no se halla tanto en la deuda, sino en el gasto. Sin cuestionar los fallos, en muchos casos inequidades, del sistema impositivo, una cosa parece cierta: el gasto del Sector Público muestra lagunas importantes de ineficiencia, que es tanto como decir de despilfarro. La escasa eficiencia es siempre inquietante, pero aún más en el Sector Público al ser financiado con impuestos de todos los ciudadanos y representar su gasto un elevado porcentaje de la renta nacional.

Fig. 1. Ingresos, gasto y deuda pública de la UE27, 2005-2012 (Miles de millones de euros)

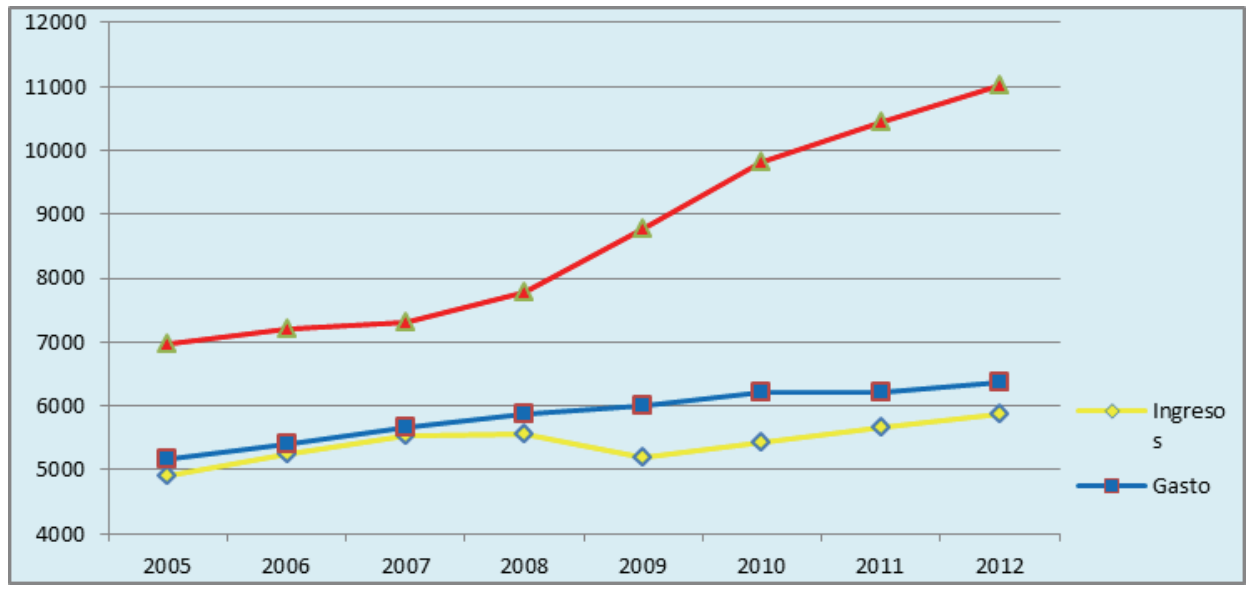

Calculando el déficit en porcentaje del PIB, que es el ratio más empleado para determinar su importancia, tenemos un incremento algo mayor que en el absoluto. En la UE27, el déficit en 2009 es un 666,7 por ciento superior al de 2007; la causa no es otra que la coincidencia del aumento de gasto con una amortiguación de la renta.

El hecho de que en los peores momentos de la recesión el origen del déficit, por el lado del gasto, continúe teniendo un carácter mayoritariamente estructural, conduce a un fenómeno presente desde 1974 y que ya hemos enunciado: el gasto público de las economías avanzadas tiende permanentemente a una expansión notable desde la 
puesta en funcionamiento del modelo socioeconómico posbélico. Esta tendencia se ha ido agudizando en el transcurso del tiempo, fundamentalmente, por los efectos sociales derivados del incremento de la renta; ello exige ritmos de crecimiento económico elevados para evitar la aparición de déficit público. En épocas recesivas ese gasto se agudiza (Gráfico 1), como sucede en 2008 y 2008, mucho más si hay que recurrir a rescates bancarios de gran envergadura, como en esta oportunidad ${ }^{18}$.

Debido a que repetir ritmos de crecimiento posbélicos es más que improbable para las economías avanzadas, el estallido del déficit en el susodicho bienio es un recordatorio traumático de que sigue sin abordarse una tarea pendiente desde 1974: acomodar el gasto a los ingresos de un crecimiento económico mucho menor que el posbélico. La respuesta a esta necesidad a partir de 2008 difícilmente puede ser otra que aumentar la presión fiscal, opción que no parece razonable, y/o controlar el incremento del gasto, lo que demanda modificar algunas funciones desempeñadas por el Estado y combatir firmemente la baja eficiencia del Sector Público. Somos conscientes de que introducir estos cambios no es tarea fácil, pero entendemos que abordarlos es de singular relevancia para que el Estado siga desarrollando una de las funciones en la que ha cosechado mayores éxitos: la cohesión social.

La eclosión del déficit en 2008 y 2009 provoca la de la deuda y sus intereses. La deuda, que ya es muy elevada en 2007 , tanto para el conjunto de la OCDE $(74,3$ por ciento del PIB) como para la UE (59,0 por ciento), se dispara en ambos organismos a partir de 2008 hasta alcanzar en 2012 el 108,8 por ciento del PIB en la OCDE y el 85,3 por ciento en la UE27. Al igual que el déficit, la deuda sobrepasa ampliamente el índice de tolerancia comunitario, la diferencia es que, mientras el déficit emprende un camino descendente a partir de 2010, la deuda no deja de crecer tanto en términos absolutos como porcentuales ${ }^{19}$, como puede observarse en el Gráfico 1. La consecuencia del incesante endeudamiento es el aumento de los intereses: si en 2007 representan el 1,6 por ciento del PIB en el conjunto de la OCDE, en 2012 tal porcentaje se eleva al 1,8 por ciento; en la UE27 se pasa en las mismas fechas del 2,7 por ciento del PIB al 2,9 por ciento ${ }^{20}$.

Lo sucedido en el déficit y la deuda merece algunos comentarios adicionales. Como ha indicado el FMI (2013: 4-8 y 46), la recesión de 2008 muestra que las economías avanzadas no están inmunizadas frente a la crisis fiscal, ésta no es patrimonio de los países en vías de desarrollo. Por otra parte, los niveles alcanzados son tan elevados que desbordan todas las proyecciones. Mas a pesar de estas cotas, los mercados

${ }^{18}$ En el caso de España y según datos del Banco de España (2013: 2), "las ayudas financieras públicas comprometidas en diversas formas de capital, desde mayo de 2009, ascienden a 61.366 millones de euros". En el de Estados Unidos, la Cámara de Representantes aprueba un plan de rescate financiero para adquirir deuda de mala calidad de los bancos por un coste de 700.000 millones de dólares.

${ }^{19}$ El volumen de deuda pública de la UE27 en 2007 asciende a 7.319.728,3 millones de euros y en 2012 a 11.011.197,0 millones.

${ }^{20}$ En la UE27 el pago de intereses de la deuda pública pasa de 338.901,9 millones de euros en 2007 a $380.254,5$ millones en 2012. 
financieros internacionales han sido capaces de afrontar este reto, eso sí, acosta de una gran dispersión en los tipos de interés que han de pagar los países deudores.

El panorama de las cuentas públicas de las economías avanzadas en 2008 y 2009 está muy lejos de ser favorable para la estabilidad económica, ni en términos de déficit ni deuda. Por el contrario, estos desajustes agudizan los desequilibrios económicos y financieros, convirtiéndose en un serio obstáculo para la recuperación económica, como hemos enunciado. La gravedad de la recesión y la toma de conciencia social y gubernamental del problema, propician que a partir de 2009 se proceda a combatir tales desajustes mediante consolidaciones fiscales mucho más severas y ambiciosas que las adoptadas en los años ochenta y noventa del siglo pasado.

Al acoplarse, en buena medida, a los informes elaborados por el FMI (2010), las diferentes consolidaciones fiscales parten de la consideración de que la recuperación requiere reducir el déficit público, y que esta reducción se ha de fundamentar en mayor medida en el ajuste de gasto que en la subida de impuestos por tener ése efectos menos distorsionadores sobre la inversión y el empleo que el incremento de la presión fiscal. Es la vía conocida como German view por ser la practicada por la Cancillería de Alemania desde el inicio de la recesión. Tómese nota de que esta opción parece chocar con las propuestas de Keynes para combatir el ciclo económico.

Las similitudes de estas consolidaciones con las realizadas en las décadas de los ochenta y noventa en la fijación de objetivos prioritarios y medidas para alcanzarlos, se pueden interpretar como el abandono definitivo por parte de las políticas públicas de la Teoría de los fallos del mercado para luchar contra las fluctuaciones económicas. La supuesta superioridad de la German view sobre las recetas de Keynes se asienta en sus mostradas limitaciones como instrumento anti cíclico y en que la realidad actual es muy diferente a la de los años treinta del siglo pasado, sobre las que se fundamenta la doctrina del profesor inglés. Estos razonamientos no carecen de lógica. No obstante, conviene hacer algunas precisiones, aunque sólo sea por respeto a la Teoría de los fallos del mercado.

Empecemos recordando que las políticas aplicadas en las décadas posteriores a la SGM no siempre son acordes con esta teoría, mucho menos las practicadas a partir de la crisis del petróleo, motivo por el que no parece razonable achacar a dicha doctrina esos fallos. En segundo término, el estado en que se hallan las cuentas públicas antes de la recesión de 2008 (acusados desequilibrios fiscales) es un escenario que en términos estrictos no es contemplado por Keynes, por cuanto está seriamente hipotecado el recurso a políticas expansivas para impulsar la demanda agregada. Finalmente, la inmediata explosión de desajustes fiscales que sigue al estallido de la crisis económica y financiera dificulta todavía más la adopción de políticas expansivas de gasto.

A pesar de que cierta falta de coherencia en la obra de ese economista inglés da pie a considerarla como un cuerpo insuficientemente cerrado (son bien conocidas sus palabras de que "uno nunca sabe lo que diré más tarde"), más si tenemos presente que reformula parte de su obra tras la SGM (Robinson, 1973: 65), lo que favorece encontradas interpretaciones de su legado, hasta el extremo de afirmarse por un Premio Nobel que "no es nada sencillo determinar cuál es realmente la doctrina del propio Keynes, ni su versión de la economía keynesiana" (Hicks, 1976: 12), a pesar de eso, entendemos que tal indefinición difícilmente es aplicable a ese apartado; su pronun- 
ciamiento en este caso es meridianamente claro, con independencia de las adhesiones o rechazos que pueda suscitar.

Retomando el cambio de rumbo que se vislumbra en la percepción de las cuentas públicas a raíz de la recesión de 2008, merece destacarse un hecho de trascendental importancia sobre este particular. Nos referimos a la decisión por parte de los países europeos de otorgar carácter institucional al principio de responsabilidad fiscal. Este es el sentido del Tratado de Estabilidad, Coordinación y Gobernanza en la Unión Económica y Monetaria, conocido por Pacto fiscal europeo.

Este Tratado intergubernamental, firmado el 2 de marzo de 2012 por todos los miembros de la UE, salvo Reino Unido y República Checa, y que entra en vigor el 1 de enero de 2013, culmina las diferentes reformas del Pacto de Estabilidad y Crecimiento, adoptado por el Consejo Europeo de Ámsterdam de junio de 1997. Para el tema que nos ocupa, el aspecto más relevante del Pacto fiscal es el compromiso de los firmantes de garantizar el equilibrio de sus cuentas públicas a partir de 2020, para lo que otorgan a este compromiso rango constitucional o similar en sus respectivos países $^{21}$.

Así se recupera institucionalmente el respeto al principio de equilibrio fiscal, defendido por el pensamiento clásico y cuestionado a partir de la recesión de 1929, y se pretende evitar el retorno de las políticas fiscales imperantes desde la crisis del petróleo. En el caso de la UE, entendemos que es la mejor prueba de que la recesión de 2008 representa el inicio de una nueva etapa presupuestaria. Si los años treinta del siglo XX han pasado a la historia de la Hacienda Pública, entre otras cosas, por romper una larga tradición de respeto al hasta entonces sacrosanto principio de responsabilidad fiscal, es probable que la crisis de 2008 pase también a la historia por clausurar más de medio siglo de políticas públicas en las que gastar permanentemente por encima de lo ingresado se había convertido en norma.

La relevancia de la depresión de 2008 se deriva de otro hecho: tanto la crisis como el combate contra ella adquieren por primera vez una dimensión global, aunque ésa afecte sobremanera a las economías avanzadas por ser las que acumulan la mayor parte de las burbujas económicas, financieras y de deuda soberana. La intensificación de las interconexiones globales que estaba teniendo lugar desde los años ochenta del siglo pasado hacía inviable que la fluctuación aparecida en los países de renta alta no terminara afectando al resto del mundo, especialmente a aquella parte con la que tal intensificación había sido mayor, las economías emergentes. Así cabe explicar que por primera vez en la historia económica se produzca una respuesta internacional a la desestabilización, prueba de ello son los encuentros internacionales destinados a coordinar las medidas anti crisis.

\footnotetext{
${ }^{21}$ La reforma del artículo 126 de la Constitución helvética en 2001 obliga al Gobierno Federal a mantener en equilibrio en el largo plazo ingresos y gastos. La Constitución de los Estados Unidos no recoge esta regla de oro, pero concede al Congreso la potestad exclusiva de incurrir en deudas, fijando éste un techo de deuda vigente hasta que el déficit aumente la deuda por encima del límite establecido.
} 
En este marco se insertan los encuentros de las grandes economías avanzadas y en vías de desarrollo, las cumbres del G20, cuya primera reunión tiene lugar en Washington en noviembre de 2008. A ésta le siguen siete más ${ }^{22}$, sobresaliendo la cuarta, celebrada en Toronto en junio de 2010, en la que los participantes concluyen que, por encima de las peculiaridades nacionales, la crisis requiere acometer ajustes físcales, principalmente de gasto, comprometiéndose a reducir el déficit público a la mitad en 2013 y, cuando menos, a estabilizar la deuda pública a partir de 2016.

Por lo tanto, en estos encuentros se abre también paso la consideración de que los desajustes fiscales agudos y permanentes son fuente de distorsiones económicas estructurales y que combatirlos mediante la contención del gasto ha de figurar entre las prioridades de las políticas públicas para salir de la recesión. Queda desestimada la oportunidad de políticas expansivas en las circunstancias presentes y más que cuestionada la tolerancia con el déficit público practicada desde 1974. Estos encuentros explicitan el carácter global de la crisis y la necesidad de dar una respuesta asimismo global al objeto de evitar su agravamiento con políticas nacionales de corte proteccionista, como sucedió en 1929.

\section{Bibliografía}

Alonso, J. A. (2005). "Equidad y crecimiento: Una relación en disputa", en Principios. Estudios de Economía Política, $\mathrm{n}^{\circ}$ 1, pp. 9-36.

Banco de España. (2013). Ayudas financieras públicas en el proceso de recapitalización del sistema bancario español (2009-2013). Madrid.

Buchanan, J. M. y Wagner, R. E. (1983). Déficit del sector público y democracia. El legado político de Lord Keynes. Edición Rialp, Madrid.

Fondo Monetario Internacional. (2010). World Economic Outlook. Fondo Monetario Internacional, Washington.

En: http://www.imf.org/external/pubs/ft/weo/2010/01/pdf/text.pdf

Fondo Monetario Internacional. (2013). Reasessing the role and modalities of fiscal policy in advanced economies. Policy Paper, 17 de septiembre.

González Temprano, A. (1998). La política de gasto social (1984-1996). CES, Madrid.

González Temprano, A. (2010). "La dimensión social del Estado intervencionista. El caso de las Comunidades Autónomas españolas", en Antonio Alonso, J. (ed.). Homenaje a Juan Muñoz. Ed. Complutense, Madrid.

Habermas, J. (1973). Problemas de legitimación en el capitalismo tardio. Amorrortu Ed, Buenos Aires.

Habermas, J. (2001). Facticidad y validez. Ed. Trotta, Madrid.

Harrison, A. J. (1991). El control del gasto público (1979-1989). Instituto de Estudios Fiscales, Madrid.

Hicks, J. (1976). La crisis de la economía keynesiana. Ed. Labor, Barcelona.

\footnotetext{
${ }^{22}$ La octava cumbre se celebró en San Petersburgo en septiembre de 2013. Se ha acordado que la novena cumbre se celebre en noviembre de 2014 en la ciudad australiana de Brisbane.
} 
Kahneman, D. (2012). Pensar rápido, pensar despacio. Debate, Barcelona.

Keynes, J. M. (1998). La teoría general del empleo, el interés y el dinero. Ed. Aosta, Madrid.

Krugman, P. et. al. (2013). Fundamentos de Economía. Ed. Reverté, Barcelona.

Lenin, V. L. (2006). El Estado y la revolución. Alianza Editorial, Madrid.

Marshall, A. (2005). Principios de Economía. Ed. Síntesis, Madrid.

Musgrave, R. y Musgrave, P. (1991). Hacienda Pública. Teórica y aplicada. McGraw Hill, Madrid.

Poulantzas, N. (1973). Poder político y clases sociales en el Estado capitalista. Siglo XXI, Madrid.

Robinson, J. (1973). La segunda crisis del pensamiento económico. Ed. Actual, México.

Samuelson, P. A. y Nordhaus, W. D. (2006). Economía. McGraw Hill, Madrid.

Smith, A. (1983). Riqueza de las naciones. Bosch, Barcelona.

Soros, G. (2008). El nuevo paradigma de los mercados financieros. Taurus, Madrid. 